\title{
The Era of PARP inhibitors in ovarian cancer: "Class Action" or not? A systematic review and meta-analysis
}

\author{
Nicoletta Staropoli $^{\mathrm{a}, 1}$, Domenico Ciliberto ${ }^{\mathrm{a}, 1}$, Teresa Del Giudice ${ }^{\mathrm{a}}$, Eleonora Iuliano ${ }^{\mathrm{a}}$, \\ Maria Cucè $^{\mathrm{a}}$, Francesco Grillone ${ }^{\mathrm{a}}$, Angela Salvino ${ }^{\mathrm{a}}$, Vito Barbieri ${ }^{\mathrm{a}}$, Antonio Russo ${ }^{\mathrm{c}}$, \\ Pierfrancesco Tassone ${ }^{\mathrm{b}}$, Pierosandro Tagliaferri ${ }^{\mathrm{a}, *}$ \\ ${ }^{a}$ Medical Oncology, Department of Experimental and Clinical Medicine, Magna Grcecia University and Cancer Center, Campus Salvatore Venuta, Catanzaro, Italy \\ b Translational Medical Oncology Unit, Department of Experimental and Clinical Medicine, Magna Grocia University and Cancer Center, Campus Salvatore Venuta, \\ Catanzaro, Italy \\ ${ }^{\mathrm{c}}$ Department of Surgical, Oncological and Oral Sciences, Section of Medical Oncology, University of Palermo, 90127 Palermo, Italy
}

\section{A R T I C L E I N F O}

\section{Keywords:}

Ovarian cancer

PARP inhibitors

Maintenance therapy

Randomized clinical trials

Meta-analysis

\begin{abstract}
A B S T R A C T
Introduction: Carboplatin is the milestone of epithelial ovarian cancer (EOC) treatment, thus response to platinum is the major prognostic factor. Among platinum-sensitive patients, $40 \%$ carry a germline or somatic BRCA1/2 mutation. In this scenario a new class of drugs, the PARP inhibitors (PARPis), produced a significant improvement in long-term disease control. In order to make an aggregate evaluation of the impact of these agents, we performed a systematic review and meta-analysis.

Patients and Methods: Clinical trials were selected by searching "Pubmed" database and abstracts from major cancer meetings. We considered the January 2008 - April 2018 time frame. Progression free survival (PFS) was the primary end-point, toxicities were secondary end-points. Hazard ratios (HRs) of PFS, with confidence intervals, and risk ratios of grade 3-4 toxicity rates, were extracted from retrieved studies and included in the current analysis. Meta-analysis was carried out by the fixed and random effect models. We conducted this metaanalysis to also compare indirectly the efficacy of different PARPis in EOC patients.

Results: Five randomized trials for a total of 1839 patients were selected and included in the final analysis. In particular, we evaluated a BRCA-mutant cohort (871 patients) with a pooled HR 0.25 (95\%CI 0.21-0.31) and the BRCA-wild type cohort (836 patients) with a pooled HR 0.41 (95\%CI 0.31-0.55), respectively. Regarding safety profile, no significant differences were detected in all grade toxicities, however, taking into account 3-4 grade toxicities and SAEs (severe adverse events), we show that rucaparib-treated patients reported major abdominal pain events, while niraparib-treated patients were associated with the highest percentage of haematological toxicities, hypothesizing a drug effect for the safety analysis. In the indirect comparisons, significant differences were not detected on PFS for the different agents.

Conclusions: We confirm a significant benefit in survival outcome of PARPis for EOC patients with a "class effect" on the bases of narrow CI and indirect comparisons in the different groups. Therefore, we underline that this strategy is of special value in BRCA-mutated patients because genetic testing allows best patient selection for all PARPis with the added value of individualized prevention in familiars.
\end{abstract}

\section{Background}

Among epithelial ovarian cancer (EOC) patients, women with genetic predisposition show an early onset of disease. Rare high penetrant mutations in BRCA1 and BRCA2 genes greatly increase lifetime risk and account for the majority of hereditary cases, $10 \%-15 \%$ of all cases.
These women have a $40-60 \%$ lifetime risk of EOC (44\% in BRCA1 families and 27\% in BRCA2 families, respectively) (Mavaddat et al., 2012; Xu et al., 2017).

The gold standard first-line treatment is still based on the combination of carboplatin/paclitaxel (du Bois et al., 1997; Jayson et al., 2014). The management of recurrent disease strictly depends on

\footnotetext{
* Corresponding author at: Medical Oncology Unit, Department of Experimental and Clinical Medicine, Magna Græcia University and Cancer Center, 88100 Catanzaro, Italy

E-mail address: tagliaferri@unicz.it (P. Tagliaferri).

${ }^{1}$ These authors contributed equally to this work.
} 
"interval from last administration of platinum cycle" (platinum free interval, PFI). In particular, patients defined as platinum-sensitive (with a PFI $>12$ months) could receive a re-challenge with platinum-based schedules (Ledermann and Kristeleit, 2010). Although a plethora of targeted agents have been evaluated, only the addition of bevacizumab, an anti-VEGF antibody monoclonal, has confirmed a role as first-line treatment and in subsequent lines of treatment (Staropoli et al., 2016).

According to different clinical and pathological behaviours, it was possible to demonstrate that the clinical outcome and prognosis of these tumors depend by molecular and pathological characteristics and by different somatic or germline mutations, unequally distributed between different subtypes (Bowtell, 2010; Kurman and Shih Ie, 2011; Nik et al., 2014).

In this scenario, BRCA mutations, both hereditary and sporadic (including BRCA loss due to promoter methylation as well as BRCA nonrelated failure in the DNA homologous recombination), reach the $40 \%$ of all cases of platinum-sensitive patients (Pinto et al., 2016). This condition seems to derive by the failure of the homologous recombination DNA repair (HRD) mechanisms (due to loss of BRCA1 function) to restore double-strand breaks induced by platinum compounds, and has been described in experimental in vitro and in vivo models (Baudi et al., 2001; Tagliaferri et al., 2009). Moreover, about $50 \%$ of sporadic EOC also display defects in the HRD pathway correlated to a good response to platinum-chemotherapy as the inherited mutations in BRCA1-2 often due to rare germline mutations in other genes involved in DNA repair (see below) (Cancer Genome Atlas Research, 2011; Tassone et al., 2005, 2009; Tassone et al., 2003).

Recently, a meta-analysis demonstrated that BRCA1/2-mutation was significantly associated with a better progression free survival (PFS), stratifying on histotype, tumour stage, sample size, duration of follow-up and optimal surgical debulking. Patients with BRCA1-mutation had significant overall survival $(\mathrm{OS})(\mathrm{HR}=0.73)$ and a significantly longer OS than non-carriers (Xu et al., 2017).

When platinum-sensitivity occurs together with positive family history and visceral involvement, this condition is defined "BRCA-ness phenotype". In all these patients there is increased reliance on the poly (ADP-ribose) polymerase (PARP) single-strand repair pathway because the cells inability to repair spontaneous and inducted DNA-damages and this effect is defined conditioned lethality (Neri et al., 2011).

Mostly, the alteration derives to loss of the normal heterozigosity of BRCA1/2 that represents an early event in the development of these cancers (Pennington et al., 2014). PARP inhibithors (PARPi) have demonstrated efficacy against EOC in women with germline mutations in BRCA1 or BRCA2 and are indicated as monotherapy for BRCA-mutated patients with platinum-sensitive recurrence (Ledermann et al., 2012). Moreover, Next Generation Sequencing (NGS) identification of somatic BRCA1/2 mutations, allows to identify a patient population with PARPi benefit in term of clinical outcomes comparable to germline BRCA1/2 mutations (Dougherty et al., 2017; Lheureux et al., 2017).

PARPi Mechanism- HRD repair is a crucial mechanism for fixing DNA double strands breaks, specifically active in the G2/S cell cycle phase in order to maintain genomic integrity. The involved genes, with loss of function, in HRD repair deficiency are BRCA1, BRCA2, RAD51C, RAD51D and BRIP1. The BRCA1/2 deficiency produces cell dependency from alternative DNA repair such as non-homologous end joining (NHEJ) and microhomology-mediated end joining (MMEJ). This alternative pathway activation increases the mutation rate and genomic instability. PARP-1 and PARP-2 are involved in DNA repair through binding to DNA single-strand breaks; this link creates a polymer that is recognized by protein involved in base excision repair (BER) pathway for repairing single strand breaks on DNA (Evans and Matulonis, 2017; Liu et al., 2017; Pulliam et al., 2018).

The PARPis are small molecules that inhibit catalytic domain and avoid the link between PARP and DNA single strand. On the rationale of specific sensitivity of EOC cells, several trials were conducted for development of this class of drugs in this disease, which demonstrated significant clinical efficacy with good safety profile (Morgan et al., 2018).

\section{Aim}

In order to assess by aggregate analysis the overall impact of PARPis in the management of EOC patients, we performed a systematic review of literature and we estimated this effect by a meta-analytic approach.

\section{Patients and methods}

\subsection{Methods}

\subsubsection{Study design}

We performed a systematic review and meta-analysis of all published RCTs to evaluate the role of PARPis schedules compared to conventional therapies and wait-watchful approach in the management of EOC. In order to compare the different PARPis, we also performed an indirect-comparison meta-analysis in accordance with The Quality of Reporting of Meta-analyses (QUOROM) statements (Moher et al., 1999). The study includes therefore only prospective and RCTs on EOC in all treatment lines with PFS, as predefined endpoint.

\subsubsection{Searching}

As performed in our previous works (Botta et al., 2017; Ciliberto et al., 2013, 2012; Ciliberto et al., 2018, 2015; Ciliberto et al., 2016; Staropoli et al., 2014, 2016), bibliographic research was conducted by PubMed, Embase, and the Central Registry of Controlled Trials of the Cochrane Library, major meeting proceeding databases (ASCO and ESMO). We identified a time frame comprises between January 2008, year of introduction of PARPis in clinical trials, and April 2018. Prospective studies only, were allowed in this analysis in order to reduce or minimize the risk of selection or information bias (Parmar et al., 1998; Stewart et al., 1998). The search was performed by the following keywords: "ovarian", "ovary", "tumor", "cancer", "advanced", "metastatic", "therapy", "PARPi", "prospective", and "randomized" in different combinations: i.e. "epithelial ovarian cancer, PARPi". The "related articles' function and references retrieved from articles were used to perform the search of all related studies, abstracts and citations. For this search papers written in English language only were considered.

\subsubsection{Selection}

In the studies included in the present review, patients had to be enrolled according to the characteristics described in Table 1.

\subsubsection{Inclusion criteria}

The studies had to report patients with diagnosis of EOC. Randomized controlled trials, with or without blinding were included. We considered abstracts or unpublished data if sufficient information on study design, characteristics of participants, interventions, and outcomes were available. In the experimental arm patients received a PARPi-based schedule. In the control arm patients received a conventional placebo maintenance for disease stage.

\subsubsection{Exclusion criteria}

Non-comparative studies; non-prospective studies; studies with noncomparable end-points were excluded.

\subsubsection{Data extraction}

The studies were examined, independently, by two investigators (N.S. and D.C.) in order to select homogeneous studies. Different variables from selected trials such as number of patients enrolled, year of publication, treatment schedule, and efficacy results were extracted and evaluated. Any discrepancy was resolved by an arbiter (P.T.). Primarily, we analyzed PFS and toxicities for all patients. Data extraction was conducted according to the PRISMA statement (Shamseer et al., 2015; 
Table 1

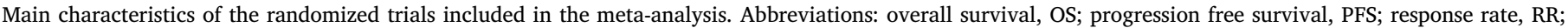
hazard ratio, HR.

\begin{tabular}{|c|c|c|c|c|c|c|c|c|c|c|}
\hline $\begin{array}{l}\text { TRIALS } \\
\text { (First author) }\end{array}$ & YEAR & TREATMENT ARMS & $\begin{array}{l}\text { TARGETED } \\
\text { PATHWAY }\end{array}$ & $\begin{array}{l}\text { PLATINUM } \\
\text { STATUS }\end{array}$ & BRCA & PATIENTS & $\begin{array}{l}\text { RR Control } \\
\text { arm }\end{array}$ & $\begin{array}{l}\text { RR Experimental } \\
\text { arm }\end{array}$ & OS & PFS \\
\hline & & & & & & & & & HR & HR \\
\hline Ledermann $\mathrm{J}$ & 2014 & Olaparib vs Placebo & PARP inhibitor & sensitive & unselected & 265 & 129 & 136 & 0.73 & 0.35 \\
\hline Ledermann $\mathrm{J}$ & 2014 & Olaparib vs Placebo & PARP inhibitor & sensitive & wt & 118 & 61 & 57 & 0.83 & 0.54 \\
\hline Ledermann $\mathrm{J}$ & 2014 & Olaparib vs Placebo & PARP inhibitor & sensitive & $\mathrm{mt}$ & 136 & 62 & 74 & 0.62 & 0.18 \\
\hline Oza A & 2014 & $\begin{array}{l}\text { Olaparib plus CHT vs } \\
\text { CHT }\end{array}$ & PARP inhibitor & sensitive & unselected & 162 & 81 & 81 & 1.17 & 0.51 \\
\hline Oza A & 2014 & $\begin{array}{l}\text { Olaparib plus CHT vs } \\
\text { CHT }\end{array}$ & PARP inhibitor & sensitive & $\mathrm{mt}$ & 41 & 21 & 20 & 1.28 & 0.21 \\
\hline Pujade-Lauraine E & 2017 & Olaparib vs Placebo & PARP inhibitor & sensitive & $\mathrm{mt}$ & 295 & 99 & 196 & & 0.3 \\
\hline Coleman RL & 2017 & Rucaparib vs Placebo & PARP inhibitor & sensitive & unselected & 564 & 189 & 375 & & 0.36 \\
\hline Coleman RL & 2017 & Rucaparib vs Placebo & PARP inhibitor & sensitive & $\mathrm{mt}$ & 196 & 66 & 130 & & 0.23 \\
\hline Coleman RL & 2017 & Rucaparib vs Placebo & PARP inhibitor & sensitive & wt & 368 & 132 & 245 & & 0.32 \\
\hline Mirza M.R. & 2017 & Niraparib vs placebo & PARP inhibitor & sensitive & $\mathrm{mt}$ & 203 & 65 & 138 & & 0.27 \\
\hline Mirza M.R. & 2017 & Niraparib vs placebo & PARP inhibitor & sensitive & wt & 350 & 116 & 234 & & 0.45 \\
\hline
\end{tabular}

Stewart et al., 2015).

\subsubsection{Validity assessment}

The quality assessment of selected studies was evaluated according to the Cochrane reviewers' handbook for six requirements: method of randomization, allocation concealment, blindness, withdrawal/ dropout, sequence generation and adequacy of follow-up (Armijo-Olivo et al., 2012; Detsky et al., 1992).

All 6 trials involved, were scored A (low risk of bias) (Table 2 Table 2).

\subsubsection{Quantitative data synthesis}

The meta-analysis was carried out in order to evaluate the effects of the PARPi-based treatments on the pre-specified end-points (Crowther et al., 2010). Regarding the outcome of patients, survival data have been extracted as HRs of PFS with relative confidence intervals (95\%CI). The interaction between survival and experimental treatment was obtained by each study from the HRs logarithm. The overall effect of combined treatments on toxicities was calculated using methods for dichotomous data (risk ratio, 95\%CI). Cochrane's Q-test and I ${ }^{2}$ statistics were used to assess heterogeneity between studies and both fixed- and random-effect models were used for the analysis taking into account the intent of comparing trials based on drugs with a possible "class effect". Pooled data significance analysis was performed according to the Mantel-Haenszel and the DerSimonian and Laird tests (Balasubramaniam and Fischgrund, 2002; DerSimonian and Levine, 1999; Jackson et al., 2010).

In order to explore the efficacy of different PARPis in the treatment of EOC, we intended to conduct an indirect-comparison meta-analysis between olaparib (at dose of $400 \mathrm{mg}$ bid and $150 \mathrm{mg}$ bid), niraparib and rucaparib. If the $95 \%$ CI limits did not overlap 1, the pooled HR or RR was considered to be statistically significant. The results of indirectcomparison could not be shown in the form of forest plot and was reported as a table.

All the statistical analyses were performed by using STATA SE v. 14.2 (STATA_Corporation, Texas, USA) (Boston and Sumner, 2003). The indirect comparison procedures of PARPis groups were conducted using the STATA-Indirect program. All tests were two-sided with $\mathrm{P} \leq$ 0.05 considered statistically significant.

\section{Results}

\subsection{Studies selection and characteristics}

In Fig. 1, the PRISMA chart related to RCTs selection and search strategy is shown. In the time-frame covered by the present systematic review (2008-2018), 497 studies were reported as full papers or meeting abstracts, while 172 studies were initially excluded because reviews and/or for trial design. Subsequently, we examined in detail the remaining 325 trials. Among them, were excluded 76 and 46 trials respectively because selection criteria were not met and overlapping of other studies. Finally, 5 trials for a total of 1839 patients were selected and included in the final analysis (Coleman et al., 2017; Ledermann et al., 2012; Mirza et al., 2016; Oza et al., 2015; Pujade-Lauraine et al., 2017).

\subsection{PFS analyses}

Regarding the survival outcome only the PFS analyses were evaluable for retrievable data. We confirm the significant benefit in terms of PFS compared to control arm. In particular, we dwell attention on sensitivity analyses and each one of subgroup. Although a significant advantage was showed in all subgroups, both in unselected setting (pooled HR 0.38 95\%CI 0.32 - 0.46) and in BRCAwt patients (pooled HR 0.41 95\%CI 0.31 - 0.55), we demonstrated that the most evident benefit of PARPis is retained in the BRCAmut population (pooled HR $0.2595 \%$ CI $0.21-0.31$ ). In particular, in this analysis the potential better performance seems to be evident for olaparib (Fig. 2).

The indirect comparison was summarized in Table 3. The indirect comparison results indicated the lack of significant differences between the different PARPis.

Table 2

Quality assessment.

\begin{tabular}{|c|c|c|c|c|c|c|c|c|}
\hline Included Studies & Year & Method Of Randomization & Allocation Concealment & Blind & Withdrawal And Dropout & Sequence Generation & Baseline & Quality Level \\
\hline Ledermann $\mathrm{J}$ & 2014 & Centralized & Central Office & Yes & Detailed Criteria & Detailed & Identical Baseline & A \\
\hline Oza A & 2014 & Centralized & Central Office & No & Detailed Criteria & Detailed & Identical Baseline & A \\
\hline Pujade-Lauraine E & 2017 & Centralized & Central Office & Yes & Detailed Criteria & Detailed & Identical Baseline & A \\
\hline Coleman RL & 2017 & Centralized & Central Office & Yes & Detailed Criteria & Detailed & Identical Baseline & $\mathrm{A}$ \\
\hline Mirza M.R & 2016 & Centralized & Central Office & Yes & Detailed Criteria & Detailed & Identical Baseline & A \\
\hline
\end{tabular}




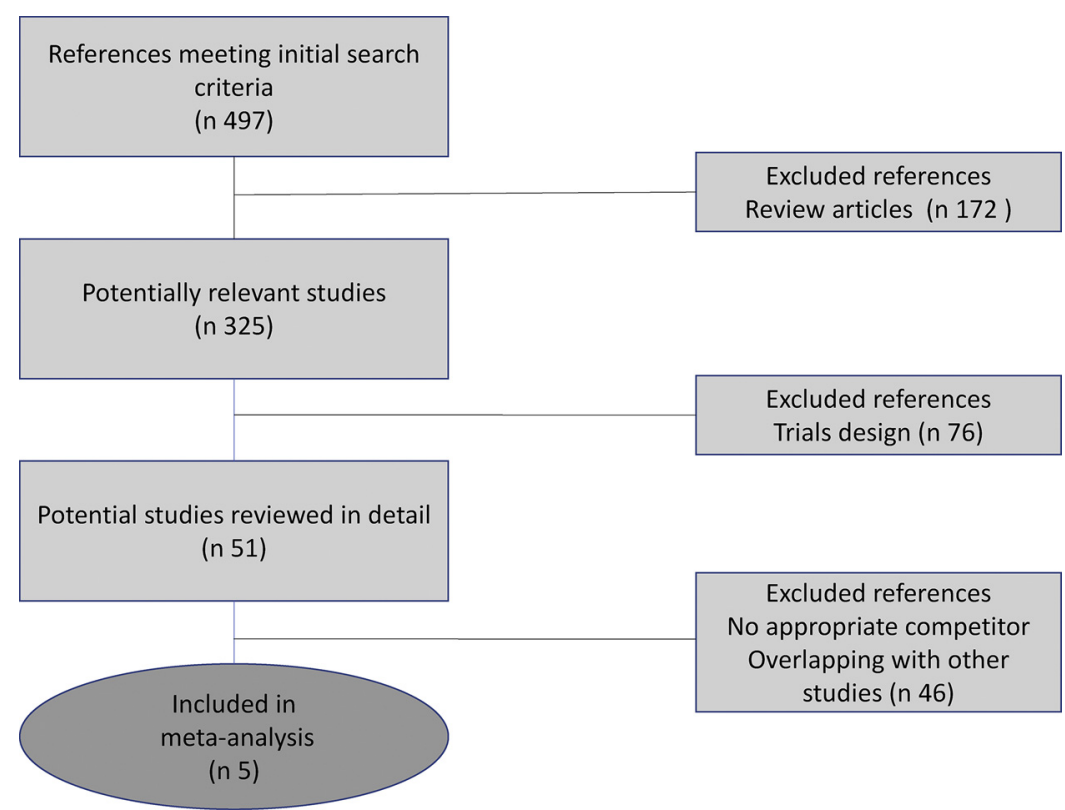

Fig. 1. PRISMA chart showing the trial exclusion and inclusion process in the meta-analysis. SEER, Surveillance, Epidemiology, and End Results.

\subsection{Toxicity analyses}

As detailed in Table 4, we confirm the class effect of PARPis in term of safety profile, considering the all grades toxicities. Conversely, if we consider the 3-4 grades toxicities and the reported SAEs, we showed the significant differences of safety profile for each one of analyzed drugs. In particular, the haematological toxicity was significantly related to niraparib while the abdominal pain for rucaparib and diarrhea for olaparib subgroups, respectively.

\section{Discussion}

This meta-analysis of 6 RCTs for a total of 1839 patients compares PARPi-based schedules to any other systemic conventional treatment and/or wait/watchful approach.

First of all, we confirmed the survival benefit for all PARPis

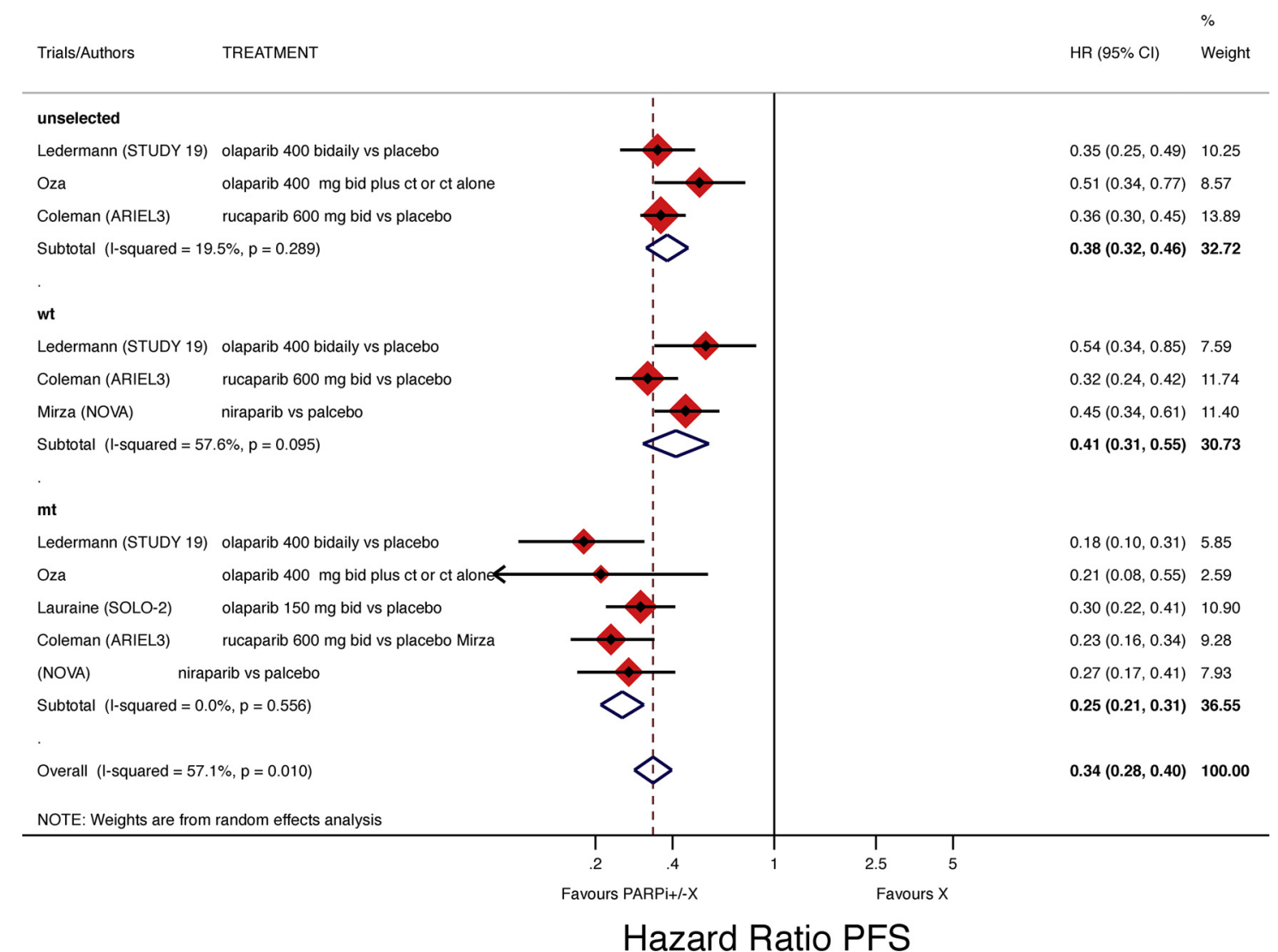

Fig. 2. Comparison of PFS according to PARPi and BRCA status Abbreviation: progression free survival, PFS; hazard ratio, HR. 
Table 3

Indirect comparison of treatments. Abbreviations: progression free survival, PFS; hazard ratio, HR; confidence interval, CI.

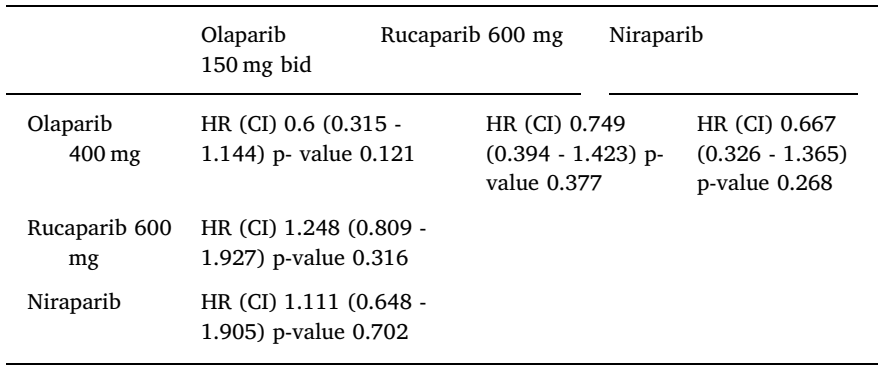

Table 4

PARPis Toxicities in all grades and 3-4 grade/SAE subgroup.

\begin{tabular}{llll}
\hline ALL GRADES & Olaparib RR (CI) & Rucaparib RR (CI) & Niraparib RR (CI) \\
\hline Abdominal Pain & $0,7(0,47-1,11)$ & $114(0,86-152)$ & $076(0,57-1,03)$ \\
Constipation & $1,24(0,6-1,87)$ & $152(114-2,03)$ & $198(144-2,72)$ \\
Diarrea & $1,62(092-2,34)$ & $145(1,06-198)$ & $092(065-1,32)$ \\
Fatigue & $1,66(1,18-2,04)$ & $157(1,32-1,87)$ & $144(1,18-1,74)$ \\
Nausea & $2,27(1,67-252)$ & $205(1,68-2,49)$ & $209(1,7-2,57)$ \\
Vomiting & $1,94(1,31-3,31)$ & $245(1,7-353)$ & $212(1,48-304)$ \\
Anemia & $5,37(2,27-9,39)$ & $637(3,54-11,47)$ & $748(4,29-13,04)$ \\
SEVERE & & & \\
Abdominal Pain & $0,84(0,15-3,11)$ & $454(0,58-35,54)$ & $065(0,15-2,87)$ \\
Constipation & 0,07 & $178(0,37-8,41)$ & $098(0,09-10,69)$ \\
& $(0,05-45,34)$ & & \\
Diarrea & 2,54 & $050(0,07-353)$ & $024(0,02-2,67)$ \\
& $(0,12-37,40)$ & & $1463(201-106,44)$ \\
Fatigue & $2,02(0,58-8,14)$ & $252(098-6,48)$ & $268(0,60-11,97)$ \\
Nausea & $5,58(0,3-93,63)$ & $706(0,93-53,25)$ & $341(0,42-27,54)$ \\
Vomiting & 2,53 & $378(0,87-16,36)$ & \\
Anemia & $(0,33-23,53)$ & & 9147 \\
& 9,60 & 3528 & $(5,71-1464,79)$ \\
\hline & $(1,93-44,73)$ & $(4,94-252,01)$ &
\end{tabular}

individually and in the pooled analysis. In particular we evaluated a BRCAmt cohort (871 patients) with a pooled HR 0.25 (95\%CI 0.21 0.31 ) and the BRCAwt cohort (836 patients) with a pooled HR 0.41 (95\%CI 0.31-0.55), in term of PFS in recurrent platinum-sensitive EOC.

Taking into account these findings, we may afford some possible explanations.Interestingly, apart from olaparib studies, all rucaparib and niraparib studies were based on different methods for the identification of the "BRCAness phenotype" (Mirza et al., 2016). However, there are some limitations: first, "BRCAness phenotype" represents "a clinical concept" that does not reflect a well-established biological or molecular definition with different gene expression and immunologic profile. Moreover, several unstandardized techniques were used in the above described trials to identify patients with HRD. This heterogeneity does not allow to aggregate all data concerning $\mathrm{LOH}$ signature in a dedicated sensitivity analysis. Therefore, we dwell attention on BRCAwt and BRCAmt patient subgroups. We found that PARPis were similar in terms of efficacy and we confirmed the major effects on BRCAmt subgroup in terms of PFS. The visual inspection of forrest plot disclosed a trend of major benefit for BRCAmt patients treated with olaparib (in Study 19 schedule). Moreover, the impact of PARPis in BRCAwt and BRCAmt cannot be evaluated on the OS endpoint taking into account that all studies were not powered for this endpoint and the limited follow-up.

In our previous analysis, we provided the correlation of BRCA overexpressed in the dataset of TCGA $(p=0.04)$, which we indirectly compared with results retrievable by subgroups analyses of PARPis studies. We demonstrated a benefit in terms of PFS that didn't reflect a real benefit in terms of OS probably due to a long survival post progression (Cancer Genome Atlas Research, 2011; Staropoli et al., 2016). All together our analysis on PFS based on narrow CI on the aggregate analyses and the indirect comparison results led us to affirm a class effect of PARPis, which does not appear to indicate a rationale for differential use in different (others) classes of patients. Also, taking to account the availability of alternative therapies in this setting, it is very important to dwell attention on the "cost benefit ratio" particularly on a clear improvement in terms of efficacy outcome and a better acceptable safety profile. In these patients, indeed, the role of maintenance therapy with chemotherapy agents or targeted therapy drugs remain still uncertain and the need to define a better strategy represent a major aim of clinical research in this area. However, despite the great attention placed on the biological and molecular profile of EOC (and in particular of HGSOC) none of the evaluated biomarkers is clinically relevant. In this scenario, the BRCA status (identified at diagnosis) represents an important biomarker not only of the PARPi-response but also as a platinum-response predictor (Tassone et al., 2009). Moreover, several findings highlighted a role of BRCA in the cytoskeletal reorganization related to the product of the proto-oncogene aurora kinase A (AURKA). AURKA and BRCA activations seem to influence many tumour suppressor proteins (p53, c-Myc), while these alterations occur very early in EOC progression (Ouchi et al., 2004; Yang et al., 2004). Recently, we demonstrated that AURKA could represent a potential biomarker, in association to BRCA status, for an earlier definition of platinum-response (Mignogna et al., 2016).

Finally, if we consider the high percentage of BRCAmt patients identified in the context of all platinum-sensitive patients, the relevance of the BRCA1 and BRCA2 gene testing in these patients allows the interception of BRCAmt families with the subsequent social impact of a personalized prevention strategy for proband and family members that is an important added value (Pinto et al., 2016).

The safety profile deserves a particular analysis. Indeed, by these findings, it is possible to observe that the "class effect" previously reported for efficacy outcome, is here well defined for "all grade toxicity" analysis only. Conversely, in the subgroup analysis conducted for 3-4 toxicity grades or SAE, the safety profile appears deeply unbalanced on different PARPis and in particular niraparib reported a relevant haematologic toxicity. It would be interesting to correlate these events with pharmaco-genomics personalized molecular profiles by the use of dedicated platforms (Arbitrio et al., 2016a, b; Di Martino et al., 2011a, b; Di Martino et al., 2016; Guzzi et al., 2012; Scionti et al., 2017).

The major limitation of this meta-analysis is the unavailable data on the OS outcome and the different biological profile of enrolled patients. Moreover, this work is performed for Literature data with other limits as the difficulty to retrieve all data relating to any subgroups, and possibility to aggregate all the data of each single study for all endpoints selected.

We conclude that the efficacy class effect does not justify expanded market approval for any of PARPis and suggest that differences in safety profile should be the major issue in drug choice.

Finally, the attempt to define a genomic signature for the "BRCAness phenotype" could represent an important future goal in the context of EOC patients for the optimal therapeutic strategy. However, this goal requires a dramatic implementation of molecular analyses and the possibility of using a universally recognized standardized method for this specific tool.

\section{Author contributions}

DC, NS, PT, and PT designed the study.

DC, NS, EI e TDG did the literature search.

DC, NS, TDG extracted data. DC realized the figures.

EI and TDG performed the tables.

All authors collected data.

DC, NS, PT, and, PT interpreted and analyzed the data, and wrote the manuscript.

All authors read and approved final version of the manuscript.

Disclosures 


\section{Acknowledgments}

This work has been supported by PhD program of Magna Graecia University: "molecular oncology and translational and innovative medical and surgical techniques".

\section{References}

Arbitrio, M., Di Martino, M.T., Barbieri, V., Agapito, G., Guzzi, P.H., Botta, C., Iuliano, E., Scionti, F., Altomare, E., Codispoti, S., Conforti, S., Cannataro, M., Tassone, P., Tagliaferri, P., 2016a. Identification of polymorphic variants associated with erlotinib-related skin toxicity in advanced non-small cell lung cancer patients by DMET microarray analysis. Cancer Chemother. Pharmacol. 77 (1), 205-209.

Arbitrio, M., Di Martino, M.T., Scionti, F., Agapito, G., Guzzi, P.H., Cannataro, M. Tassone, P., Tagliaferri, P., 2016b. DMET (Drug Metabolism Enzymes and Transporters): a pharmacogenomic platform for precision medicine. Oncotarget 7 (33), 54028-54050.

Armijo-Olivo, S., Stiles, C.R., Hagen, N.A., Biondo, P.D., Cummings, G.G., 2012. Assessment of study quality for systematic reviews: a comparison of the cochrane collaboration risk of Bias tool and the effective public health practice project quality assessment tool: methodological research. J. Eval. Clin. Pract. 18 (1), 12-18.

Balasubramaniam, M., Fischgrund, J.S., 2002. Two-tailed Fisher's exact test (CochranMantel-Haenzel). Spine J. 2 (2), 158-159.

Baudi, F., Quaresima, B., Grandinetti, C., Cuda, G., Faniello, C., Tassone, P., Barbieri, V., Bisegna, R., Ricevuto, E., Conforti, S., Viel, A., Marchetti, P., Ficorella, C., Radice, P., Costanzo, F., Venuta, S., 2001. Evidence of a founder mutation of BRCA1 in a highly homogeneous population from southern Italy with breast/ovarian cancer. Hum. Mutat. 18 (2), 163-164.

Boston, R.C., Sumner, A.E., 2003. STATA: a statistical analysis system for examining biomedical data. Adv. Exp. Med. Biol. 537, 353-369.

Botta, C., Ciliberto, D., Rossi, M., Staropoli, N., Cuce, M., Galeano, T., Tagliaferri, P., Tassone, P., 2017. Network meta-analysis of randomized trials in multiple myeloma: efficacy and safety in relapsed/refractory patients. Blood Adv. 1 (7), 455-466.

Bowtell, D.D., 2010. The genesis and evolution of high-grade serous ovarian cancer. Nat. Rev. Cancer 10 (11), 803-808.

Cancer Genome Atlas Research, N., 2011. Integrated genomic analyses of ovarian carcinoma. Nature 474 (7353), 609-615.

Ciliberto, D., Prati, U., Roveda, L., Barbieri, V., Staropoli, N., Abbruzzese, A., Caraglia, M., Di Maio, M., Flotta, D., Tassone, P., Tagliaferri, P., 2012. Role of systemic chemotherapy in the management of resected or resectable colorectal liver metastases: a systematic review and meta-analysis of randomized controlled trials. Oncol. Rep. 27 (6), 1849-1856.

Ciliberto, D., Botta, C., Correale, P., Rossi, M., Caraglia, M., Tassone, P., Tagliaferri, P., 2013. Role of gemcitabine-based combination therapy in the management of advanced pancreatic cancer: a meta-analysis of randomised trials. Eur. J. Cancer 49 (3), 593-603.

Ciliberto, D., Staropoli, N., Caglioti, F., Gualtieri, S., Fiorillo, L., Chiellino, S., De Angelis, A.M., Mendicino, F., Botta, C., Caraglia, M., Tassone, P., Tagliaferri, P., 2015. A systematic review and meta-analysis of randomized trials on the role of targeted therapy in the management of advanced gastric cancer: Evidence does not translate? Cancer Biol. Ther. 16 (8), 1148-1159.

Ciliberto, D., Staropoli, N., Chiellino, S., Botta, C., Tassone, P., Tagliaferri, P., 2016. Systematic review and meta-analysis on targeted therapy in advanced pancreatic cancer. Pancreatology 16 (2), 249-258.

Ciliberto, D., Staropoli, N., Caglioti, F., Chiellino, S., Ierardi, A., Ingargiola, R., Botta, C., Arbitrio, M., Correale, P., Tassone, P., Tagliaferri, P., 2018. The best strategy for RAS wild-type metastatic colorectal cancer patients in first-line treatment: a classic and Bayesian meta-analysis. Crit. Rev. Oncol. Hematol. 125, 69-77.

Coleman, R.L., Oza, A.M., Lorusso, D., Aghajanian, C., Oaknin, A., Dean, A., Colombo, N., Weberpals, J.I., Clamp, A., Scambia, G., Leary, A., Holloway, R.W., Gancedo, M.A. Fong, P.C., Goh, J.C., O'Malley, D.M., Armstrong, D.K., Garcia-Donas, J., Swisher, E.M., Floquet, A., Konecny, G.E., McNeish, I.A., Scott, C.L., Cameron, T., Maloney, L., Isaacson, J., Goble, S., Grace, C., Harding, T.C., Raponi, M., Sun, J., Lin, K.K., Giordano, H., Ledermann, J.A., investigators, A., 2017. Rucaparib maintenance treatment for recurrent ovarian carcinoma after response to platinum therapy (ARIEL3): a randomised, double-blind, placebo-controlled, phase 3 trial. Lancet 390 (10106), 1949-1961.

Crowther, M., Lim, W., Crowther, M.A., 2010. Systematic review and meta-analysis methodology. Blood 116 (17), 3140-3146.

DerSimonian, R., Levine, R.J., 1999. Resolving discrepancies between a meta-analysis and a subsequent large controlled trial. JAMA : the journal of the American Medical Association 282 (7), 664-670.

Detsky, A.S., Naylor, C.D., O’Rourke, K., McGeer, A.J., L’Abbe, K.A., 1992. Incorporating variations in the quality of individual randomized trials into meta-analysis. J. Clin. Epidemiol. 45 (3), 255-265.

Di Martino, M.T., Arbitrio, M., Guzzi, P.H., Leone, E., Baudi, F., Piro, E., Prantera, T., Cucinotto, I., Calimeri, T., Rossi, M., Veltri, P., Cannataro, M., Tagliaferri, P., Tassone, P., 2011a. A peroxisome proliferator-activated receptor gamma (PPARG) polymorphism is associated with zoledronic acid-related osteonecrosis of the jaw in multiple myeloma patients: analysis by DMET microarray profiling. Br. J. Haematol. 154 (4), 529-533.

Di Martino, M.T., Arbitrio, M., Leone, E., Guzzi, P.H., Rotundo, M.S., Ciliberto, D., Tomaino, V., Fabiani, F., Talarico, D., Sperlongano, P., Doldo, P., Cannataro, M.,
Caraglia, M., Tassone, P., Tagliaferri, P., 2011b. Single nucleotide polymorphisms of ABCC5 and ABCG1 transporter genes correlate to irinotecan-associated gastrointestinal toxicity in colorectal cancer patients: a DMET microarray profiling study. Cancer Biol. Ther. 12 (9), 780-787.

Di Martino, M.T., Scionti, F., Sestito, S., Nicoletti, A., Arbitrio, M., Hiram Guzzi, P., Talarico, V., Altomare, F., Sanseviero, M.T., Agapito, G., Pisani, A., Riccio, E. Borrelli, O., Concolino, D., Pensabene, L., 2016. Genetic variants associated with gastrointestinal symptoms in Fabry disease. Oncotarget 7 (52), 85895-85904.

Dougherty, B.A., Lai, Z., Hodgson, D.R., Orr, M.C.M., Hawryluk, M., Sun, J., Yelensky, R. Spencer, S.K., Robertson, J.D., Ho, T.W., Fielding, A., Ledermann, J.A., Barrett, J.C., 2017. Biological and clinical evidence for somatic mutations in BRCA1 and BRCA2 as predictive markers for olaparib response in high-grade serous ovarian cancers in the maintenance setting. Oncotarget.

du Bois, A., Luck, H.J., Meier, W., Mobus, V., Costa, S., Richter, B., Warm, M., Bauknecht, T., Schroder, W., Olbricht, S., Nitz, U., Jackisch, C., 1997. Carboplatin/paclitaxel versus cisplatin/paclitaxel as first-line chemotherapy in advanced ovarian cancer: an interim analysis of a randomized phase III trial of the Arbeitsgemeinschaft Gynakologische Onkologie Ovarian Cancer Study Group. Semin. Oncol. 24 (5 Suppl. 15) S15-44-S15-52.

Evans, T., Matulonis, U., 2017. PARP inhibitors in ovarian cancer: evidence, experience and clinical potential. Ther. Adv. Med. Oncol. 9 (4), 253-267.

Guzzi, P.H., Agapito, G., Di Martino, M.T., Arbitrio, M., Tassone, P., Tagliaferri, P., Cannataro, M., 2012. DMET-analyzer: automatic analysis of Affymetrix DMET data. BMC Bioinformatics 13, 258.

Jackson, D., White, I.R., Thompson, S.G., 2010. Extending DerSimonian and Laird's methodology to perform multivariate random effects meta-analyses. Stat. Med. 29 (12), 1282-1297.

Jayson, G.C., Kohn, E.C., Kitchener, H.C., Ledermann, J.A., 2014. Ovarian cancer. Lancet 384 (9951), 1376-1388.

Kurman, R.J., Shih Ie, M., 2011. Molecular pathogenesis and extraovarian origin of epithelial ovarian cancer-shifting the paradigm. Hum. Pathol. 42 (7), 918-931.

Ledermann, J.A., Kristeleit, R.S., 2010. Optimal treatment for relapsing ovarian cancer. Ann. Oncol. 21 (Suppl. 7), vii218-222.

Ledermann, J., Harter, P., Gourley, C., Friedlander, M., Vergote, I., Rustin, G., Scott, C., Meier, W., Shapira-Frommer, R., Safra, T., Matei, D., Macpherson, E., Watkins, C., Carmichael, J., Matulonis, U., 2012. Olaparib maintenance therapy in platinumsensitive relapsed ovarian cancer. N. Engl. J. Med. 366 (15), 1382-1392.

Lheureux, S., Bruce, J.P., Burnier, J.V., Karakasis, K., Shaw, P.A., Clarke, B.A., Yang, S.Y., Quevedo, R., Li, T., Dowar, M., Bowering, V., Pugh, T.J., Oza, A.M., 2017. Somatic BRCA1/2 Recovery as a Resistance Mechanism After Exceptional Response to Poly (ADP-ribose) Polymerase Inhibition. J. Clin. Oncol. 35 (11), 1240-1249.

Liu, C.H., Chang, Y., Wang, P.H., 2017. Poly(ADP-ribose) polymerase (PARP) inhibitors and ovarian cancer. Taiwan J. Obstet. Gynecol. 56 (5), 713-714.

Mavaddat, N., Barrowdale, D., Andrulis, I.L., Domchek, S.M., Eccles, D., Nevanlinna, H., Ramus, S.J., Spurdle, A., Robson, M., Sherman, M., Mulligan, A.M., Couch, F.J., Engel, C., McGuffog, L., Healey, S., Sinilnikova, O.M., Southey, M.C., Terry, M.B., Goldgar, D., O'Malley, F., John, E.M., Janavicius, R., Tihomirova, L., Hansen, T.V., Nielsen, F.C., Osorio, A., Stavropoulou, A., Benitez, J., Manoukian, S., Peissel, B., Barile, M., Volorio, S., Pasini, B., Dolcetti, R., Putignano, A.L., Ottini, L., Radice, P., Hamann, U., Rashid, M.U., Hogervorst, F.B., Kriege, M., van der Luijt, R.B., Hebon Peock, S., Frost, D., Evans, D.G., Brewer, C., Walker, L., Rogers, M.T., Side, L.E., Houghton, C., Embrace Weaver, J., Godwin, A.K., Schmutzler, R.K., Wappenschmidt, B., Meindl, A., Kast, K., Arnold, N., Niederacher, D., Sutter, C., Deissler, H., Gadzicki, D., Preisler-Adams, S., Varon-Mateeva, R., Schonbuchner, I., Gevensleben, H., Stoppa-Lyonnet, D., Belotti, M., Barjhoux, L., Collaborators, G.S., Isaacs, C., Peshkin, B.N., Caldes, T., de la Hoya, M., Canadas, C., Heikkinen, T., Heikkila, P., Aittomaki, K., Blanco, I., Lazaro, C., Brunet, J., Agnarsson, B.A., Arason, A., Barkardottir, R.B., Dumont, M., Simard, J., Montagna, M., Agata, S., D'Andrea, E., Yan, M., Fox, S., kConFab, I., Rebbeck, T.R., Rubinstein, W., Tung, N., Garber, J.E., Wang, X., Fredericksen, Z., Pankratz, V.S., Lindor, N.M., Szabo, C., Offit, K., Sakr, R., Gaudet, M.M., Singer, C.F., Tea, M.K., Rappaport, C., Mai, P.L., Greene, M.H., Sokolenko, A., Imyanitov, E., Toland, A.E., Senter, L., Sweet, K., Thomassen, M., Gerdes, A.M., Kruse, T., Caligo, M., Aretini, P., Rantala, J., von Wachenfeld, A., Henriksson, K., Collaborators, S.-B., Steele, L., Neuhausen, S.L., Nussbaum, R., Beattie, M., Odunsi, K., Sucheston, L., Gayther, S.A., Nathanson, K., Gross, J., Walsh, C., Karlan, B., Chenevix-Trench, G., Easton, D.F., Antoniou, A.C., Consortium of Investigators of Modifiers of, B, 2012. Pathology of breast and ovarian cancers among BRCA1 and BRCA2 mutation carriers: results from the Consortium of Investigators of Modifiers of BRCA1/2 (CIMBA). Cancer Epidemiol. Biomarkers Prev. 21 (1), 134-147.

Mignogna, C., Staropoli, N., Botta, C., De Marco, C., Rizzuto, A., Morelli, M., Di Cello, A., Franco, R., Camastra, C., Presta, I., Malara, N., Salvino, A., Tassone, P., Tagliaferri, P., Barni, T., Donato, G., Di Vito, A., 2016. Aurora Kinase A expression predicts platinum-resistance and adverse outcome in high-grade serous ovarian carcinoma patients. J. Ovarian Res. 9 (1), 31.

Mirza, M.R., Monk, B.J., Herrstedt, J., Oza, A.M., Mahner, S., Redondo, A., Fabbro, M., Ledermann, J.A., Lorusso, D., Vergote, I., Ben-Baruch, N.E., Marth, C., Madry, R., Christensen, R.D., Berek, J.S., Dorum, A., Tinker, A.V., du Bois, A., Gonzalez-Martin, A., Follana, P., Benigno, B., Rosenberg, P., Gilbert, L., Rimel, B.J., Buscema, J., Balser, J.P., Agarwal, S., Matulonis, U.A., Investigators, E.-O.N., 2016. Niraparib Maintenance Therapy in Platinum-Sensitive, Recurrent Ovarian Cancer. N. Engl. J. Med. 375 (22), 2154-2164.

Morgan, R.D., Clamp, A.R., Evans, D.G.R., Edmondson, R.J., Jayson, G.C., 2018. PARP inhibitors in platinum-sensitive high-grade serous ovarian cancer. Cancer Chemother. Pharmacol. 81 (4), 647-658.

Neri, P., Ren, L., Gratton, K., Stebner, E., Johnson, J., Klimowicz, A., Duggan, P., Tassone, P., Mansoor, A., Stewart, D.A., Lonial, S., Boise, L.H., Bahlis, N.J., 2011. Bortezomib- 
induced "BRCAness" sensitizes multiple myeloma cells to PARP inhibitors. Blood 118 (24), 6368-6379.

Nik, N.N., Vang, R., Shih Ie, M., Kurman, R.J., 2014. Origin and pathogenesis of pelvic (ovarian, tubal, and primary peritoneal) serous carcinoma. Annu. Rev. Pathol. 9, 27-45.

Ouchi, M., Fujiuchi, N., Sasai, K., Katayama, H., Minamishima, Y.A., Ongusaha, P.P., Deng, C., Sen, S., Lee, S.W., Ouchi, T., 2004. BRCA1 phosphorylation by Aurora-A in the regulation of G2 to M transition. J. Biol. Chem. 279 (19), 19643-19648.

Oza, A.M., Cibula, D., Benzaquen, A.O., Poole, C., Mathijssen, R.H., Sonke, G.S., Colombo, N., Spacek, J., Vuylsteke, P., Hirte, H., Mahner, S., Plante, M., Schmalfeldt, B., Mackay, H., Rowbottom, J., Lowe, E.S., Dougherty, B., Barrett, J.C., Friedlander, M., 2015. Olaparib combined with chemotherapy for recurrent platinum-sensitive ovarian cancer: a randomised phase 2 trial. Lancet Oncol. 16 (1), 87-97.

Parmar, M.K., Torri, V., Stewart, L., 1998. Extracting summary statistics to perform metaanalyses of the published literature for survival endpoints. Stat. Med. 17 (24), 2815-2834.

Pennington, K.P., Walsh, T., Harrell, M.I., Lee, M.K., Pennil, C.C., Rendi, M.H., Thornton, A., Norquist, B.M., Casadei, S., Nord, A.S., Agnew, K.J., Pritchard, C.C., Scroggins, S., Garcia, R.L., King, M.C., Swisher, E.M., 2014. Germline and somatic mutations in homologous recombination genes predict platinum response and survival in ovarian, fallopian tube, and peritoneal carcinomas. Clin. Cancer Res. 20 (3), 764-775.

Pinto, C., Bella, M.A., Capoluongo, E., Carrera, P., Clemente, C., Colombo, N., Cortesi, L., De Rosa, G., Fenizia, F., Genuardi, M., Gori, S., Guarneri, V., Marchetti, A., Marchetti, P., Normanno, N., Pasini, B., Pignata, S., Radice, P., Ricevuto, E., Russo, A., Tagliaferri, P., Tassone, P., Truini, M., Varesco, L., 2016. Recommendations for the implementation of BRCA testing in the care and treatment pathways of ovarian cancer patients. Future Oncol. 12 (18), 2071-2075.

Pujade-Lauraine, E., Ledermann, J.A., Selle, F., Gebski, V., Penson, R.T., Oza, A.M., Korach, J., Huzarski, T., Poveda, A., Pignata, S., Friedlander, M., Colombo, N., Harter, P., Fujiwara, K., Ray-Coquard, I., Banerjee, S., Liu, J., Lowe, E.S., Bloomfield, R., Pautier, P., investigators, S.O.E.-O, 2017. Olaparib tablets as maintenance therapy in patients with platinum-sensitive, relapsed ovarian cancer and a BRCA1/2 mutation (SOLO2/ENGOT-Ov21): a double-blind, randomised, placebo-controlled, phase 3 trial. Lancet Oncol. 18 (9), 1274-1284.

Pulliam, N., Fang, F., Ozes, A.R., Tang, J., Adewuyi, A., Keer, H.N., Lyons, J.F., Baylin, S.B., Matei, D., Nakshatri, H., Rassool, F.V., Miller, K.D., Nephew, K.P., 2018. An effective Epigenetic-PARP inhibitor combination therapy for breast and ovarian cancers independent of BRCA-mutations. Clin. Cancer Res.

Scionti, F., Di Martino, M.T., Sestito, S., Nicoletti, A., Falvo, F., Roppa, K., Arbitrio, M. Guzzi, P.H., Agapito, G., Pisani, A., Riccio, E., Concolino, D., Pensabene, L., 2017.
Genetic variants associated with Fabry disease progression despite enzyme replacement therapy. Oncotarget 8 (64), 107558-107564.

Shamseer, L., Moher, D., Clarke, M., Ghersi, D., Liberati, A., Petticrew, M., Shekelle, P., Stewart, L.A., Group, P.-P., 2015. Preferred reporting items for systematic review and meta-analysis protocols (PRISMA-P) 2015: elaboration and explanation. Bmj 350, g7647.

Staropoli, N., Ciliberto, D., Botta, C., Fiorillo, L., Grimaldi, A., Lama, S., Caraglia, M., Salvino, A., Tassone, P., Tagliaferri, P., 2014. Pegylated liposomal doxorubicin in the management of ovarian cancer: a systematic review and metaanalysis of randomized trials. Cancer Biol. Ther. 15 (6), 707-720.

Staropoli, N., Ciliberto, D., Chiellino, S., Caglioti, F., Giudice, T.D., Gualtieri, S., Salvino, A., Strangio, A., Botta, C., Pignata, S., Tassone, P., Tagliaferri, P., 2016. Is ovarian cancer a targetable disease? A systematic review and meta-analysis and genomic data investigation. Oncotarget 7 (50), 82741-82756.

Stewart, L.A., Parmar, M.K., Tierney, J.F., 1998. Meta-analyses and large randomized, controlled trials. N. Engl. J. Med. 338 (1), 61 author reply 61-62.

Stewart, L.A., Clarke, M., Rovers, M., Riley, R.D., Simmonds, M., Stewart, G., Tierney, J.F., Group, P.-I.D., 2015. Preferred reporting items for systematic review and metaanalyses of individual participant data: the PRISMA-IPD statement. JAMA :J. Am. Med. Assoc. 313 (16), 1657-1665.

Tagliaferri, P., Ventura, M., Baudi, F., Cucinotto, I., Arbitrio, M., Di Martino, M.T., Tassone, P., 2009. BRCA1/2 genetic background-based therapeutic tailoring of human ovarian cancer: hope or reality? J. Ovarian Res. 2, 14.

Tassone, P., Tagliaferri, P., Perricelli, A., Blotta, S., Quaresima, B., Martelli, M.L., Goel, A. Barbieri, V., Costanzo, F., Boland, C.R., Venuta, S., 2003. BRCA1 expression modulates chemosensitivity of BRCA1-defective HCC1937 human breast cancer cells. Br. J. Cancer 88 (8), 1285-1291.

Tassone, P., Blotta, S., Palmieri, C., Masciari, S., Quaresima, B., Montagna, M., D'Andrea, E., Eramo, O.P., Migale, L., Costanzo, F., Tagliaferri, P., Venuta, S., 2005. Differential sensitivity of BRCA1-mutated HCC1937 human breast cancer cells to microtubuleinterfering agents. Int. J. Oncol. 26 (5), 1257-1263.

Tassone, P., Di Martino, M.T., Ventura, M., Pietragalla, A., Cucinotto, I., Calimeri, T., Bulotta, A., Neri, P., Caraglia, M., Tagliaferri, P., 2009. Loss of BRCA1 function increases the antitumor activity of cisplatin against human breast cancer xenografts in vivo. Cancer Biol. Ther. 8 (7), 648-653.

Xu, K., Yang, S., Zhao, Y., 2017. Prognostic significance of BRCA mutations in ovarian cancer: an updated systematic review with meta-analysis. Oncotarget 8 (1), 285-302.

Yang, H., Ou, C.C., Feldman, R.I., Nicosia, S.V., Kruk, P.A., Cheng, J.Q., 2004. Aurora-A kinase regulates telomerase activity through c-Myc in human ovarian and breast epithelial cells. Cancer Res. 64 (2), 463-467. 